\title{
An energy storage and rapid charge system using EDLC for the Solar Light Rail
}

\author{
T. Kameya ${ }^{1,2}$, J. Uddin $^{3}$, G. Suzuki ${ }^{4} \&$ H. Katsuma ${ }^{5}$ \\ ${ }^{I}$ Tama Art University, Japan \\ ${ }^{2}$ Tokyo University of Technology, Japan \\ ${ }^{3}$ Coppin State University, USA \\ ${ }^{4}$ Tokyo Denki University (Retiree), Japan \\ ${ }^{5}$ Shonan Research Center for Light Rail Transit, Japan
}

\begin{abstract}
"The Solar Light Rail" is a proposed power supply method for a 100\% renewable energy light rail system. Experiments using a prototype model were carried out in all four seasons in order to verify whether the proposed system can function effectively throughout the day. The primary electric double layer capacitor (EDLC) unit, with a breakdown voltage of $17.5 \mathrm{~V}$ and a capacitance of $171.4 \mathrm{~F}$, is charged by solar panels. The secondary EDLC unit which has a breakdown voltage of $15.0 \mathrm{~V}$ and a capacitance of $100 \mathrm{~F}$ is mounted on the railcar and is charged rapidly by the primary EDLC. The railcar leaves and returns on a straight rail of 9 meters by charged energy, and the secondary EDLC is charged from the primary EDLC again. It was confirmed that the proposed power supply method was effective even in a climate with little or no sunshine, and also that it is necessary to raise the breakdown voltage and capacitance of the primary EDLC to ensure long-term operation after sunset.
\end{abstract}

Keywords: renewable energy, transportation, energy storage, electric double layer capacitor, rechargeable.

\section{Introduction}

Railways are known as environmentally friendly transportation system. $\mathrm{CO}_{2}$ emission and energy consumption of rail transport is lower than that of road transport [1]. Moreover, a light rail (known as tram, streetcar) does not divide the town like a railway and people can cross a rail easily. A light rail is friendly not 
only for environment but also for people. However, fossil fuel power generation accounts for over $60 \%$ of all electric power in Japan. When railways, especially light rails, can run on renewable energy such as solar, wind and hydro power, it will be more eco-friendly transportation system.

In most of previous works to make railways run on renewable energy especially solar power, solar panels are installed along the rail in order to obtain accepted electricity, and electricity is supplied to the railcar in real time [1,2].

A rechargeable run system named "The Solar Light Rail" is proposed [3-5]. Figure 1 shows the power supply method of this system. Solar panels are installed on the roof and around the station. Wind turbines and water wheels are built around the station. Straight blade vertical axis wind turbines are suitable for this system, since wind turbine noise is less than that of horizontal axis wind turbines $[6,7]$. A unit of electric double layer capacitor (EDLC), called as "the primary EDLC," is installed at the station as an energy storage device, and the primary EDLC is always charged from solar panels, wind turbines and water wheels. There is a short contact wire for rapid charge at the station [8]. An EDLC unit, called as "the secondary EDLC," is mounted on a railcar. When the railcar stops at the station, electricity is rapidly transmitted from the primary EDLC to the secondary EDLC. The railcar charges electricity only to reach the next station at each stop. In this system, energy storage devices repeat charge and discharge. Advantages of an EDLC such as long life, high input-output power and low pollution [9, 10], are suitable for this system. The amount of energy stored per unit weight is lower than that of batteries. However, usually distance between stations of light rails is shorter than that of railways. Therefore, that cannot become disadvantage in this system.

According to the test outcome by the Railway Technical Research Institute of Japan, their hybrid light rail vehicle named "Hi-tram" consumes $2.5 \mathrm{kWh}$ of electricity per kilometers at the maximum air conditioning load $[11,12]$. If the Solar Light Rail line is assumed as follows, the power generation capacity of $99,000 \mathrm{kWh}$ is required a year at each station.

- Interval between stations is $500 \mathrm{~m}$.

- A railcar arrives and departs every 10 minutes.

- The operation time is 6:00 to 24:00.

If required electric power can be supplied, it is feasible in the calculation to run the light rail only by renewable energy [3]. Experiments were carried out using a prototype model in order to substantiate the proposal.

In this paper, experiments using a prototype model were carried out in winter, spring, summer and autumn order to verify whether the proposed power supply system can function effectively throughout the day.

\section{Experimental equipment}

Figure 2 shows the experimental equipment. 


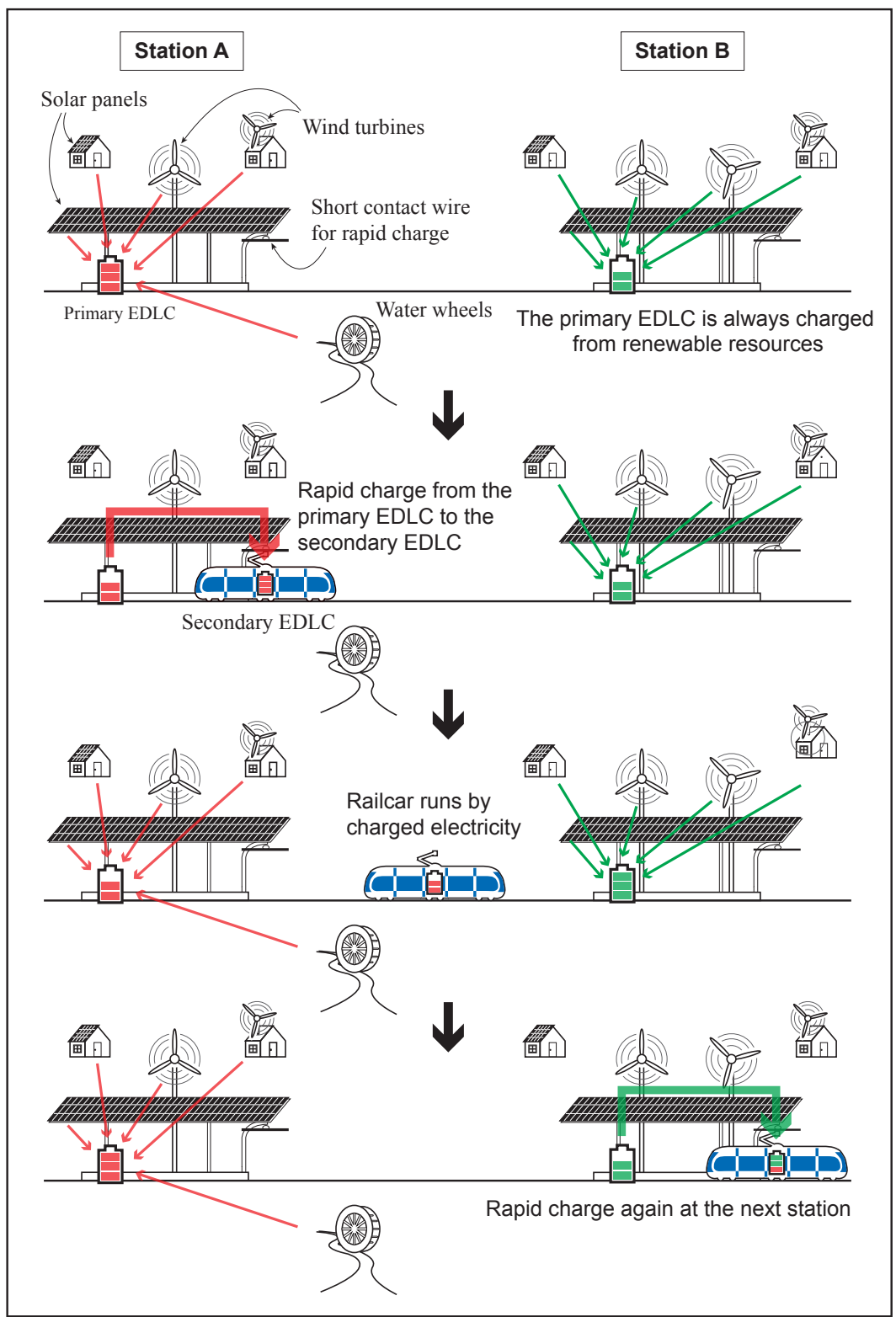

Figure 1: Power supply method of the Solar Light Rail. 


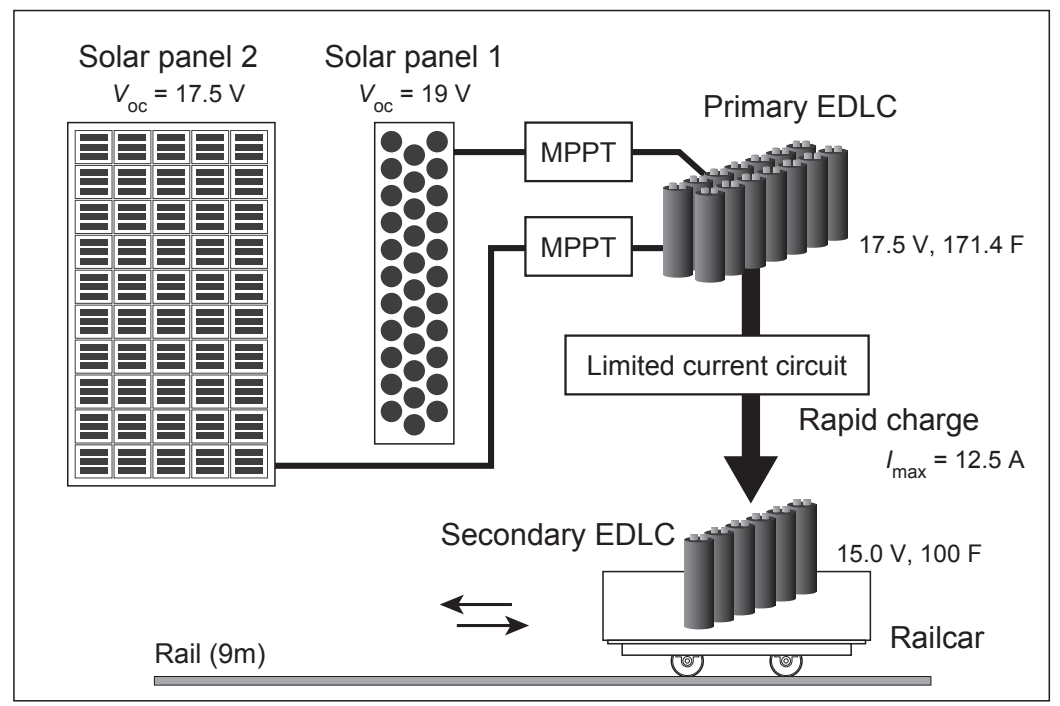

Figure 2: The experimental equipment.

\subsection{Solar panels}

Two types of solar panels are used as a generator in the experiments. One is a mono-crystalline silicon solar panel. Eleven circular cells are wired in series, and three sets of wired cells are connected in parallel. Although the solar panel has been used more than 20 years, open circuit voltage of $19 \mathrm{~V}$ and short circuit current of $3 \mathrm{~A}$ are still measured in preliminary experiments. This solar panel is called as "solar panel 1" in this paper.

Another is a poly-crystalline silicon solar panel. This solar panel is fabricated with 50 solar cells. Ten rectangular cells are wired in series, and five sets of wired cells are connected in parallel. Open circuit current of $17.5 \mathrm{~V}$ and short circuit current of 3 A are measured. This solar panel is called as "solar panel 2" in this paper.

\subsection{EDLC unit}

EDLC units are fabricated with cylindrical cells of 2.5 V - 600 F. Seven EDLC cells are wired in series, and two sets of EDLC wired in series are connected in parallel for the primary EDLC. The primary EDLC becomes the breakdown voltage of 17.5 V and the capacitance of 171.4 F. Six EDLC cells are wired in series for the secondary EDLC. The secondary EDLC becomes the breakdown voltage of $15.0 \mathrm{~V}$ and the capacitance of $100 \mathrm{~F}$. A resistor of $1 \mathrm{k} \Omega$ is wired in parallel for each EDLC cell as a voltage balancing resistor. 


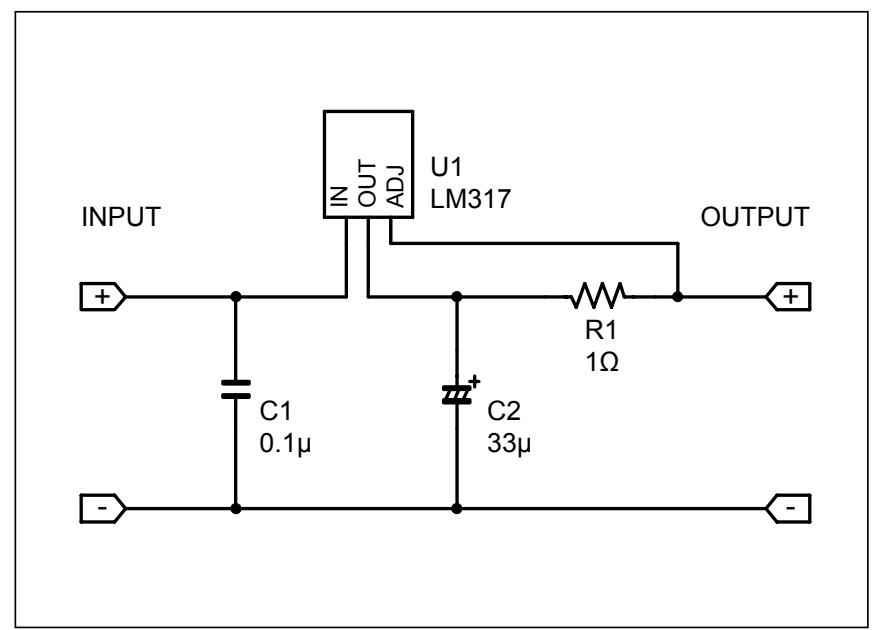

Figure 3: A circuit diagram of the limited current circuit (1 unit).

\subsection{Limited current circuit}

An excessive electric current flows when the primary EDLC is connected to the secondary EDLC directly. A limited current circuit is installed between the primary EDLC and the secondary EDLC for safety. The three terminal regulator of LM317 has constant current characteristic as eqn (1) [13].

$$
I_{O U T}=\frac{V_{R E F}}{R 1}
$$

$V_{R E F}$ of LM317 is $1.25 \mathrm{~V}$ [13], so that limited current of the circuit shown as Figure 3 is $1.25 \mathrm{~A}$. The limited current circuit of $12.5 \mathrm{~A}$ is made connecting ten these circuits in parallel.

\subsection{Railcar}

A railcar is fabricated in standard of 5-inches gauge model railroad, the possible smallest size for riding. The size of railcar is $934 \mathrm{~mm}$ in length, $450 \mathrm{~mm}$ in width and $339 \mathrm{~mm}$ in height. The wheel base is $375 \mathrm{~mm}$. A DC motor of $40 \mathrm{~W}$ is mounted on the four-wheel car

\section{Experiment}

\subsection{Experimental method}

Solar panels are put on the ground horizontally under the experiments. The primary EDLC is charged by solar panel 1 and 2. The first rapid charge is carried out when 


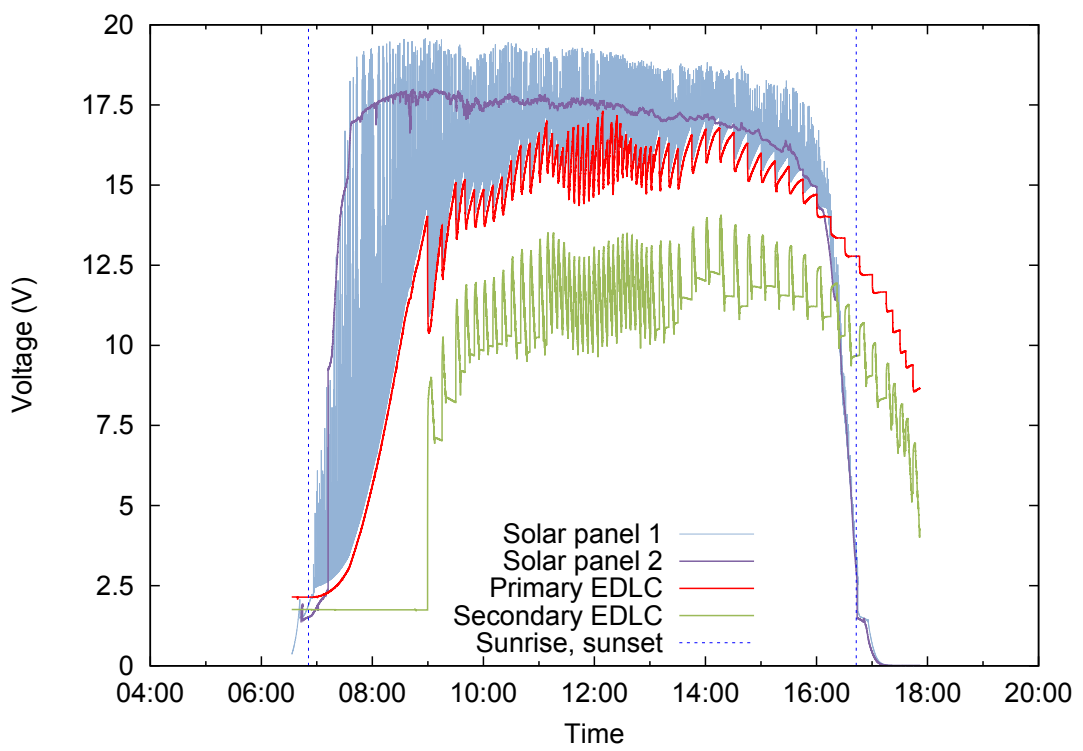

Figure 4: Transition of the voltage under the experiment on January 6, 2013.

the voltage of the primary EDLC reaches $14 \mathrm{~V}$. The author, weight of $65 \mathrm{~kg}$, rides the railcar, and then the railcar goes and returns 3 times (at the first experiment) or 5 times (at other experiments) on the strait rail of $9 \mathrm{~m}$. Thereafter, rapid charge and running repeats every 15 minutes.

The open circuit voltage of the solar panel 1 is higher than the breakdown voltage of the primary EDLC. Therefore, the interval of rapid charge and round trips per charge has to be changed in order to consume more electricity and keep the voltage of the primary EDLC lower than the breakdown voltage.

The experiment finishes when the railcar is not able to complete 3 or 5 times round trips. The number of rapid charges and round trips are counted, and the voltage of solar panel 1, solar panel 2, primary EDLC, and secondary EDLC are also recorded by data acquisition system (IOtech Personnel Daq/55).

Four experiments were carried out at Hachioji Campus, Tokyo University of Technology (Tokyo, Japan).

\subsection{January 6, 2013}

The first experiment was carried out on January 6, 2013. It was the 16th day after the winter solstice. The sunrise of the day was 6:51 and the sunset was 16:43 at Tokyo [14]. It was sunny or bit cloudy in the morning, however, it became cloudy in the afternoon. The highest temperature of the day at Hachioji was $9.2^{\circ} \mathrm{C}$ and the lowest temperature was $-5.2^{\circ} \mathrm{C}[15]$. 


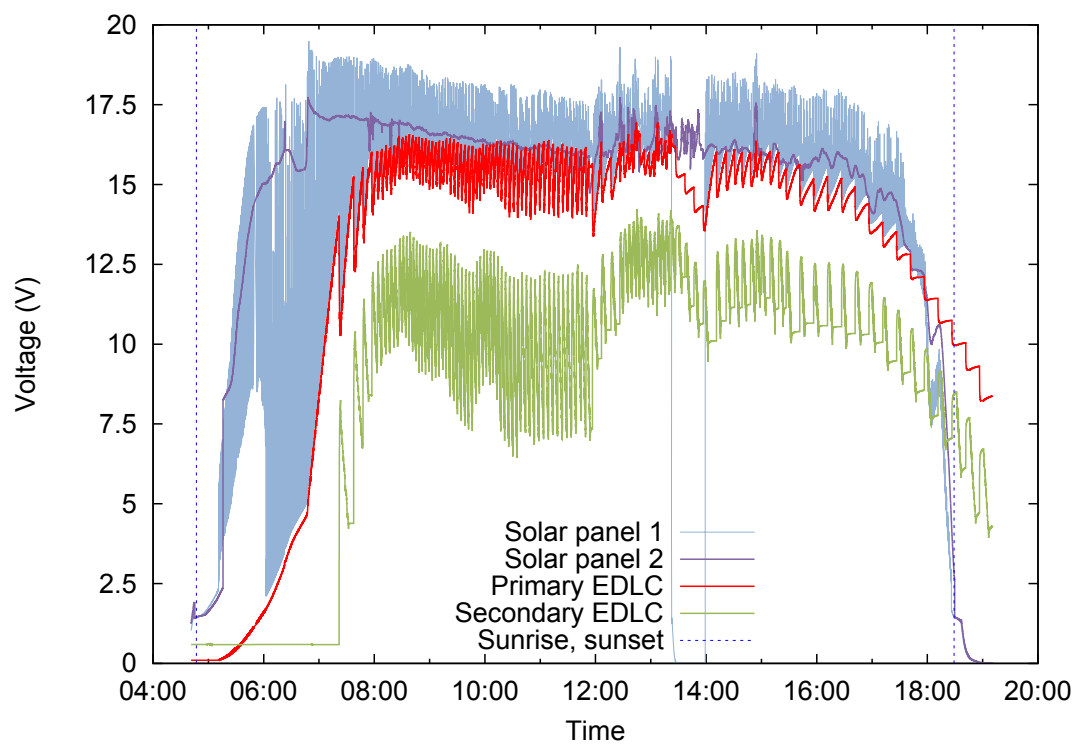

Figure 5: Transition of the voltage under the experiment on May 3, 2013.

Figure 4 shows the transition of the voltage under the experiment. When the experiment started, the voltage of the primary EDLC was $2.1 \mathrm{~V}$ and the voltage of the secondary EDLC was $1.8 \mathrm{~V}$. The voltage of primary EDLC reached $14.0 \mathrm{~V}$ at $8: 59$ and the first rapid charge was carried out.

The voltage of solar panel 2 fell lower than the voltage of the primary EDLC at 16:08 and the voltage of solar panel 1 fell lower than the voltage of the primary EDLC at 16:13. Rapid charges were carried out 9 times after 16:13 and 7 times after sunset. The last rapid charge was carried out at 17:44 and the railcar stopped at 17:52. The voltage of primary EDLC was $8.7 \mathrm{~V}$ and the voltage of secondary EDLC was $4.3 \mathrm{~V}$.

The interval of rapid charge was 5 minutes after 17:15, because charging from solar panels was not expected at that time. The last rapid charge was carried out 18:15 when interval of 15 minutes was kept. This system functioned for 1.5 hours after sunset.

In this experiment, rapid charge was carried out 56 times, and the railcar completed 236 round trips.

\subsection{May 3, 2013}

The second experiment was carried out on May 3, 2013. The sunrise of the day was 4:47 and the sunset was 18:29 at Tokyo [14]. Figure 5 shows the transition of the voltage under the experiment. When the experiment started, the voltage of the 


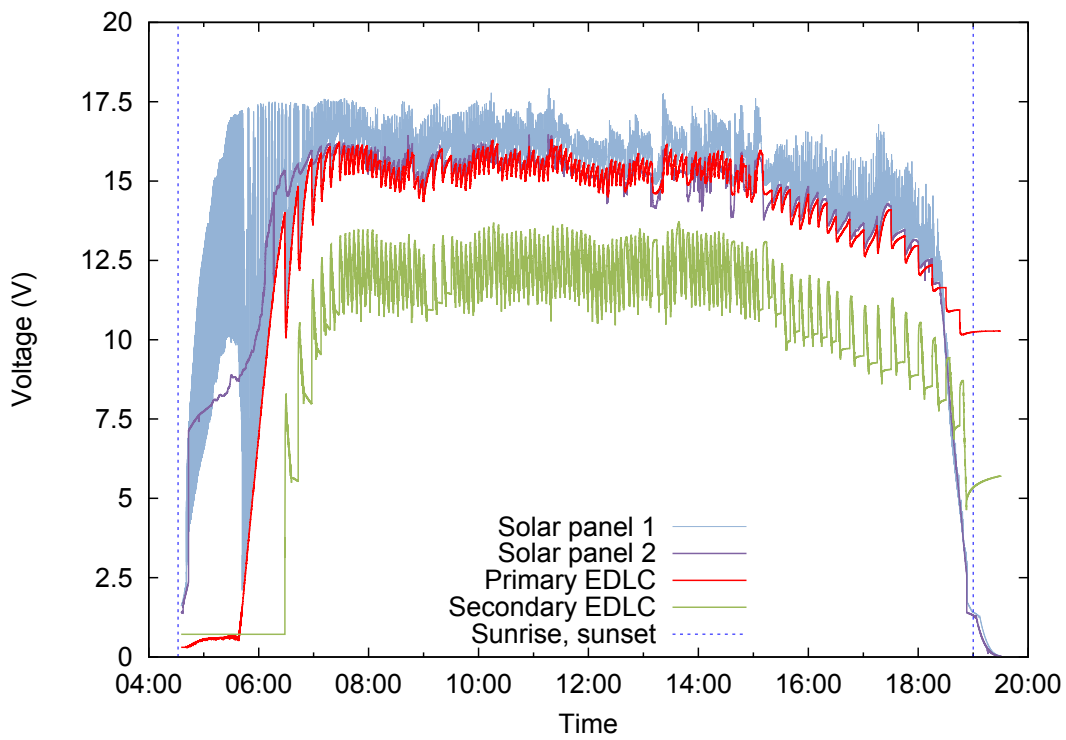

Figure 6: Transition of the voltage under the experiment on July 7, 2013.

primary EDLC was $0.1 \mathrm{~V}$ and the voltage of the secondary EDLC was $0.6 \mathrm{~V}$. The first rapid charge was carried out at 7:21.

The solar panel 1 had to be disconnected from 13:22 to 13:59, since the voltage of the primary EDLC exceeded $16.5 \mathrm{~V}$.

The last rapid charge was carried out at 18:56 and the railcar stopped at 19:06. The voltage of primary EDLC was $8.3 \mathrm{~V}$ and the voltage of secondary EDLC was $4.2 \mathrm{~V}$. In this experiment, rapid charge was carried out 101 times, and the railcar completed 505 round trips.

\subsection{July 7, 2013}

The third experiment was carried out on July 7, 2013. It was the 15 th day after the summer solstice. The sunrise of the day was 4:32 and the sunset was 19:00 at Tokyo [14]. Figure 6 shows the transition of the voltage under the experiment.

When the experiment started, the voltage of the primary EDLC was $0.3 \mathrm{~V}$ and the voltage of the secondary EDLC was $0.7 \mathrm{~V}$. There was a mistake of the cable connection, and the primary EDLC was not charged. The voltage of the primary EDLC was raised after the correction at 5:39, and the first rapid charge was carried out at $6: 28$.

The last rapid charge was carried out at 18:45 and the railcar stopped at 18:52. The voltage of primary EDLC was $10.2 \mathrm{~V}$ and the voltage of secondary EDLC was $4.9 \mathrm{~V}$. In this experiment, rapid charge was carried out 110 times, and the railcar completed 551.5 round trips. 


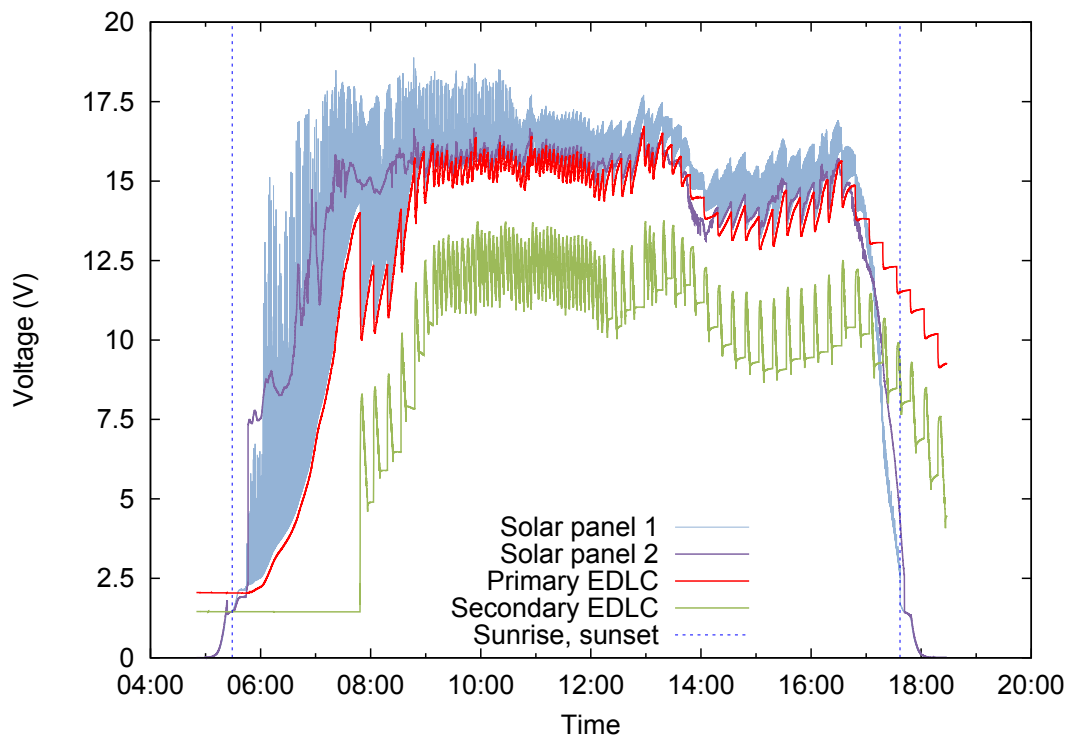

Figure 7: Transition of the voltage under the experiment on September 23, 2013.

\subsection{September 23, 2013}

The fourth experiment was carried out on September 23, 2013. It was the autumnal equinox. The sunrise of the day was 5:29 and the sunset was 17:37 at Tokyo [14]. Figure 7 shows the transition of the voltage under the experiment. When the experiment started, the voltage of the primary EDLC was $2.1 \mathrm{~V}$ and the voltage of the secondary EDLC was $1.5 \mathrm{~V}$. The first rapid charge was carried out at 7:48.

It was cloudy all the day. The last rapid charge was carried out at 18:18 and the railcar stopped at 18:26. The voltage of primary EDLC was $9.3 \mathrm{~V}$ and the voltage of secondary EDLC was $4.4 \mathrm{~V}$. In this experiment, rapid charge was carried out 72 times, and the railcar completed 361.5 round trips.

\section{Discussion}

\subsection{Evaluation of the power supply system}

Rapid charges from the primary EDLC to the secondary EDLC with the limited current circuit could be carried out. Although the experiments were carried out under disadvantages for photovoltaic - it was only two weeks after of the winter solstice, it was cloudy and solar panels were put horizontally - the railcar ran for more than 9 hours. It was confirmed that the proposed power supply system functions effectively throughout a day. 


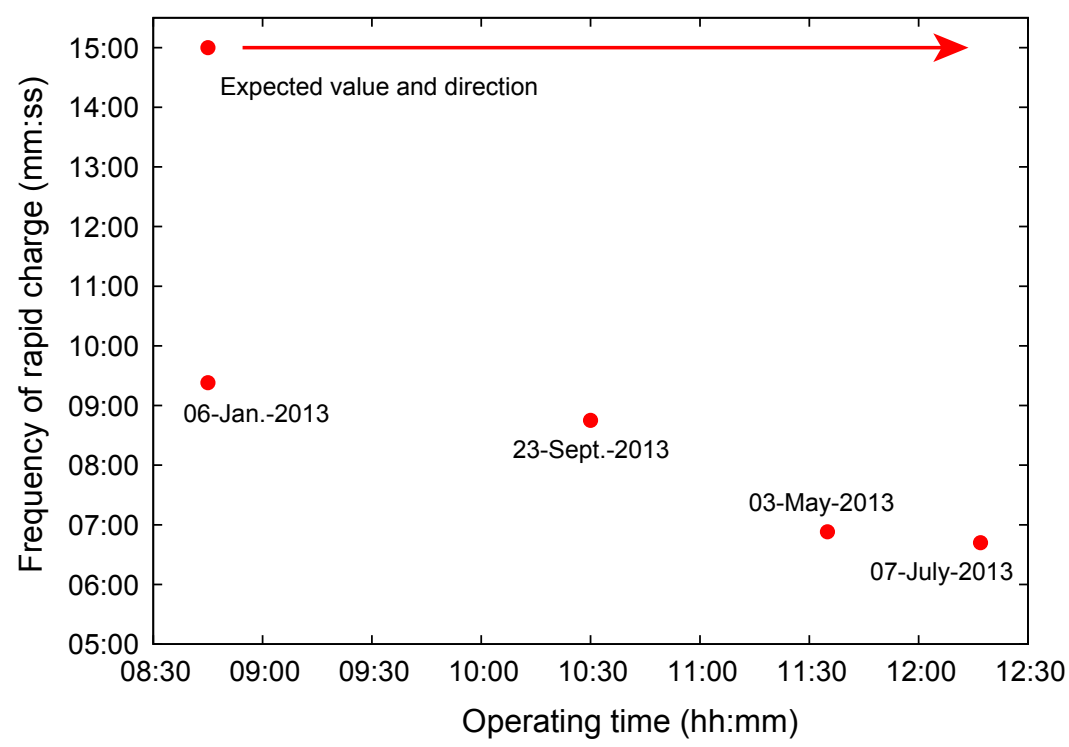

Figure 8: Operating time and frequency of rapid charge.

\subsection{For the long-term operation after sunset}

On January 6, 2013, the first rapid charge was carried out at 8:59, and the last rapid charge was carried out was carried out at 17:44. The operating time of the day was 8 hours and 45 minutes. Similarly, the operating time became 11 hours and 35 minutes for the second experiment, 12 hours and 17 minutes for the third experiment and 10 hours and 30 minutes for the fourth experiment.

The rapid charges were carried out 56 times in 8 hours and 45 minutes under the first experiment. It means a rapid charge was carried out every 9 minutes and 23 seconds. Similarly, the frequency of rapid charge became 6 minutes and 53 seconds for the second experiment, 6 minutes and 42 seconds for the third experiment and 8 minutes and 45 seconds for the fourth experiments.

Figure 8 shows the operating time and frequency of rapid charge. The frequency of rapid charge becomes higher with longer operating time. It means that the electricity is not stored for the operation after sunset. Although the interval of rapid charge was 15 minutes under the regulation of the experiments, the interval had to be changed since the breakdown voltage of the primary EDLC was lower than the open circuit voltage of the solar panel 1. The frequency of rapid charge and the operating time will get better by rise in the breakdown voltage of the primary EDLC. And also, it is required to raise the capacitance of the primary EDLC for long-term operation after sunset [16]. 


\section{Conclusions}

In summary, demonstration experiments were carried out with a prototype model in winter, spring, summer and autumn.

From the experiments carried out under disadvantages for photovoltaic, it was confirmed that the proposed power supply system functions effectively throughout a day.

It is required to raise the breakdown voltage and the capacitance of the primary EDLC for long-term operation after sunset.

The experiments using a scale model which applied law of similarity is required to verify the energy consumption in this energy supply system.

\section{References}

[1] Jaffery, S.H.I., Khan, H.A., Khan, M. \& Ali, S., A study on the feasibility of solar powered railway system for light weight urban transport. World Renewable Energy Forum (WREF) 2012, ed. C. Fellows, American Solar Energy Society: Denver, USA, volume 3, pp. 1892-1896, 2012.

[2] Fujii, O., Solar train-hybrid truck system. Technical Report of Kurume Institute of Technology, 27, pp. 39-47, 2004. In Japanese.

[3] Kameya, T., Kezuka, H., Suzuki, G. \& Katsuma, H., The solar light rail. World Renewable Energy Forum (WREF) 2012, ed. C. Fellows, American Solar Energy Society: Denver, USA, volume 2, pp. 1047-1053, 2012.

[4] Kameya, T., Suzuki, G. \& Katsuma, H., Proposal of suitable LRT for Okinawa using natural energy. The 4th International Workshop on Light Rail Transit, Organizing Committee on LRT WORKSHOP 2010: Okinawa, Japan, 2010. In Japanese.

[5] Kameya, T., Suzuki, G., Harada, Y. \& Katsuma, H., Basic experiment concerning a rail transport system using natural energy. Tama Art University Bulletin, 24, pp. 91-102, 2010. In Japanese.

[6] Seki, K., Study of straight wing non-articulated vertical axis wind turbine system and its starting characteristics. Wind Energy, 25(1), pp. 52-55, 2001. In Japanese.

[7] Sagara, K., Nomoto, K., Sasahara, Y. \& Seki, K., An application of straight blade non-articulated vertical axis wind turbine generation systems. Wind Energy, 27(4), pp. 16-19, 2003. In Japanese.

[8] Mori, I., Hori, Y. \& Asaoka, S., Capacitor trolley bus in Shanghai. ECaSS Forum, 3, pp. 2-8, 2008. In Japanese.

[9] Okamura, M., Electric Double Layer Capacitor and Charging System. Nikkan Kogyo Shimbun Ltd.: Tokyo, Japan, 3rd edition, 2005. In Japanese.

[10] Ochiai, T., Study on the electric double layer capacitors. Master's thesis, Tokyo Denki University, Tokyo, Japan, 2000. In Japanese.

[11] Ogasa, M., LRT technology up to date 1. Rolling Stock $\mathcal{E}$ Technology, 16(8), pp. 18-23, 2010. In Japanese. 
[12] Taguchi, Y. \& Ogasa, M., An estimation method of SOC of lithium-ion battery for contact-wire and battery hybrid electric railway vehicle. RTRI Report, 26(10), pp. 35-40, 2012. In Japanese.

[13] National Semiconductor Corporation, LM317A/LM317 3-terminal adjustable regulator. Datasheet, 2007.

[14] Ephemeris Computation Office, National Astronomical Observatory of Japan. http://eco.mtk.nao.ac.jp/koyomi/index.html.en.

[15] Japan Meteorological Agency, Weather statics information. http:// www.data.jma.go.jp/obd/stats/etrn/index.php.

[16] Takizawa, K. \& Kondo, K., Study of method for designing the power and the capacitance of fuel cells and electric double-layer capacitors of hybrid railway vehicle. IEEJ Transactions on Industry Applications, 132(2), pp. 133-139, 2012. In Japanese. 